\title{
Research on Recruitment Model Based on Person-Organization Fit
}

\author{
Zhen Cheng ${ }^{1}$ \\ ${ }^{1}$ School of Management, Shanghai University of Engineering Science, Shanghai, China \\ Correspondence: Zhen Cheng, School of Management, Shanghai University of Engineering Science, Shanghai \\ 201600, China. Tel: 86-153-1671-1995. E-mail: cz520xy@163.com
}

Received: February 27, 2014

Accepted: March 4, $2014 \quad$ Online Published: March 9, 2014

doi:10.5430/ijba.v5n2p126

URL: http://dx.doi.org/10.5430/ijba.v5n2p126

\begin{abstract}
Person-organization fit is a hot problem in the study on human resource management and organizational behavior. To recruit and keep talents who fit company's development will be key to maintain sustainable development and competitiveness and origin.Traditional human resource management focus on person-position fit.People carry out a large number of person-position fit study and apply it to practice. In recent years, researchers begin to realize, in order to achieve the ideal effect, not only should we pay attention to person-position fit, but also attaches great importance to the good matching between individual and organization. This article puts forward new recruitment strategy of the person-organization fit. New recruitment strategy emphasis the research of Person-organization fit should change from theory research to application research, from single to multiple measurement, from simple to complex relations, from the individual level to the organizational level.
\end{abstract}

Keywords: person-position fit, recruitment pattern, person-organization fit

\section{Background}

In today's world, with the rapid development of science and technology, knowledge economy has became the trend of times.International competitions are increasingly competitive. In the wake of economic globalization and knowledge economy age, not only comprehensive national strength between countries. But also the focus of competition among enterprises have gradually transferred onto the knowledge of science and technology as the core competitiveness. The most prominent competition in science and technology is embodied in human resources. Therefore, how to recruit and retain the talents whom fits the line with the development of organization has became the center and root of maintaining sustainable development and competitiveness. In traditional recruitment, it emphasizes on matching people with positions. This recruitment is often referred to person-position fit. It is key to ensure the individual compatible with a particular work and pursue the best matching of employee knowledge, skills and abilities (KSAs) and specific job requirements. But in the new era of knowledge economy, human resources have become the first resource to promote social development. Therefore, the person-position fit recruitment model is increasingly highlighted. Because it solely focuses on a specific job to selecting suitable candidates. And ignoring the individual employees and other organizational factors have an impact on organizational development. Meanwhile, without putting people into a particular environment considerations, which also resulted in that organizations usually ignore many factors about human characteristics which are not directly relate to work in the recruitment process. So we can not estimate the matching degree between recruiters individual and organizational culture, values. Therefore, changes of the traditional recruitment model become necessary. What's more, The Person-organization fit recruitment model is more and more attention by researchers. Individuals and organizations to match (person-organization fit) concept is proposed and carried out in a lot of researches.

In-depth study of Person-organization fit recruitment model. Not only apply it to enterprise and improve the efficiency of enterprises, but also have important practical significance in the process of recruitment. Especially in the domestic enterprises, when enterprises facing the competition of foreign capital enterprise, how to attract and retain key talents under the condition of employee benefits is less than foreign capital enterprise.

In terms of theoretical research, Person-organization fit recruitment strategy can effectively make up for the deficiency of recruitment research. Meanwhile, it also rich the theory system of the person-organization fit recruitment model, so we can have a better understand and use. 


\section{The Connotation and Characteristics of Person-Organization Fit}

\subsection{The Connotation of Person-Organization Fit Recruitment Model}

Person-organization fit recruitment model, referring to the cooperation between the individual and the organization. But the meaning of individuals and organizations are extremely complex in the study. Chatman think that it should be understood based on the interactive point of view. His organizational model shown in Figure 1, he thinks the organizations attract employees with similar characteristics, and select them into the organization. With the passage of time, the staff who characteristics conflict with organization can leave the organization, so the homogeneity of organization gradually increase, heterogeneity gradually decrease. This model indicates that the results of Person-organization fit can improve the organizational behavior, norms and values and personal values, attitudes. However, more and more researchers pay attention to the point of view in compatibility between individuals and organizations.

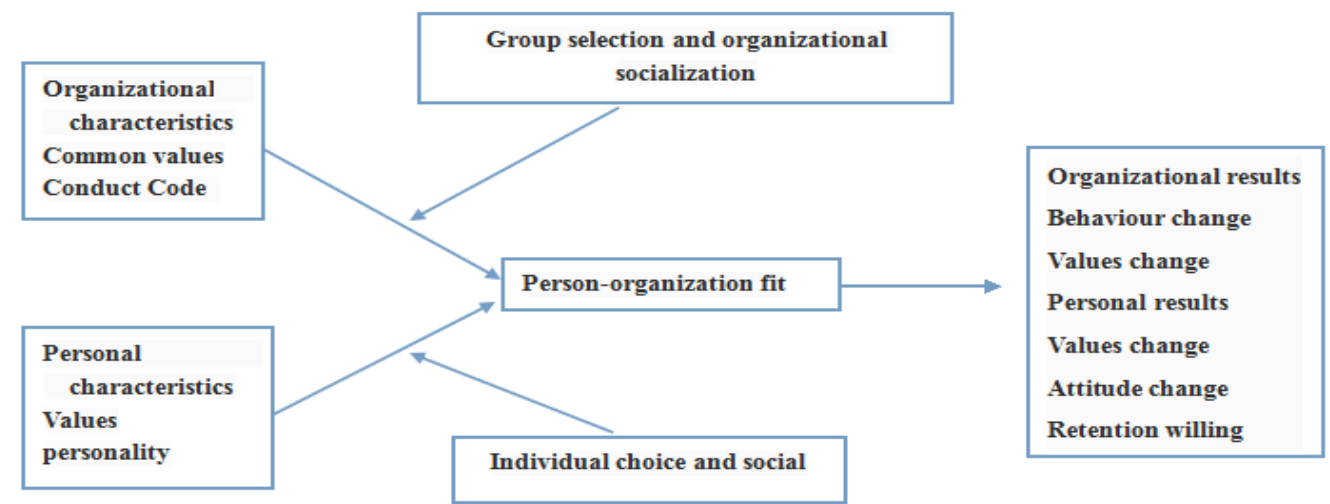

Figure 1. Chatman person-organization fit model

Kristof comprehensively analysis the concept of Person-organization fit, and put up with the model that the integration of the individual and the organization. In Figure 2, the model will match the point of consistency matching and complementarity matching, Requirement-ability and Demand - supply.All of these relationships are integrated. Kristof believes that individuals and organizations matching will achieve in the following three cases: First, one part of individuals or organizations have met the needs of the other; Second, the basic characteristics of the individual and the organization have the same or similar part; Third, this case is along with the first two cases. In another way, this case possesses the characteristics of the first two cases.

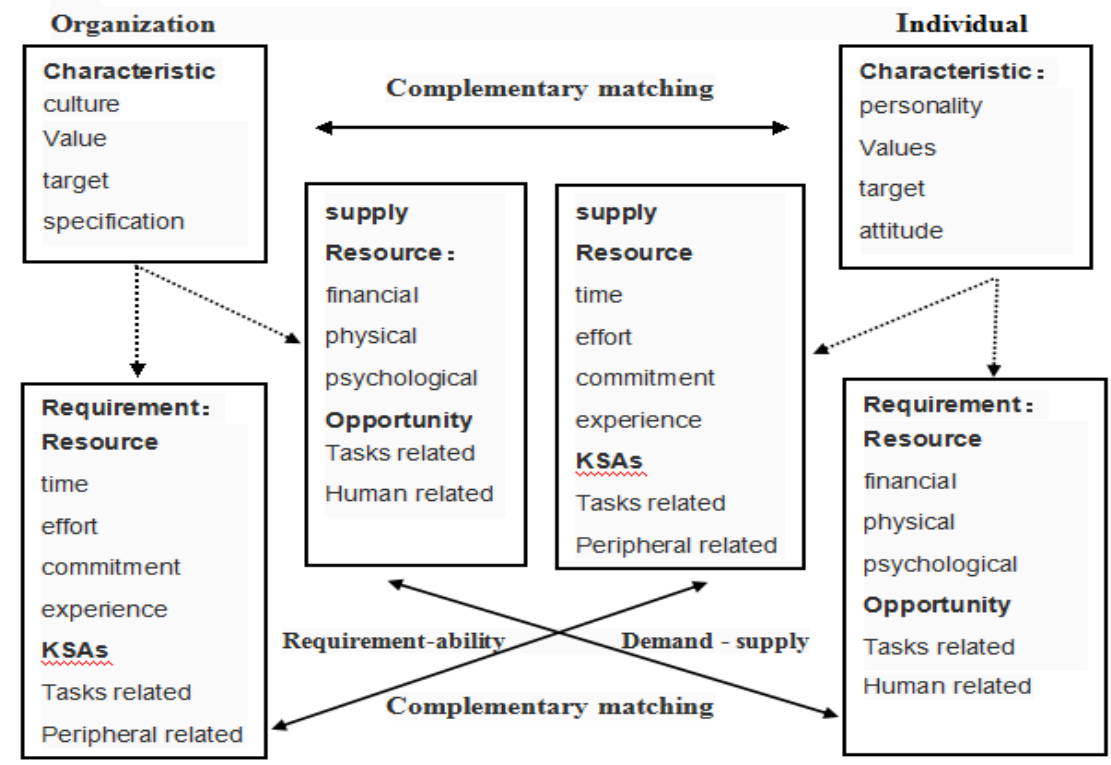

Figure 2. Kristof person-organization fit model 


\subsection{The Characteristics of Person-Organization Fit Recruitment Model}

When we realized the difference between person-position fit and person-organization fit, we will easily find the characteristics of the person-organization fit recruitment.

The traditional model of recruitment on the basis of person-position fit fails to consider the fit of organizational culture and individual character, which result in the appearances of a series of questions of human resource management. The main limitation of it can be summarized as these cases: First, individual job performance is often used as the result of personal KSAs and tasks matching.Second, this model focuses on the discovery of new staff recruitment while ignoring retain qualified staff. What's more, in the recruitment process, Managers did not pay attention to whether the staff agree that organizational culture and values.

Compared with the traditional model of recruitment, person-organization fit recruitment model is based on the sufficient interaction of people and organizations. The advantages can be summarized as follows: First, it improve the work performance of employees.Second, it also improve employees' work attitude. When employee's values and goals according to the organization, staff will generate a sense of responsibility and belonging.Third, it can help companies to retain talents and reduce the turnover rate.

\section{Process Analysis of Person-Organization Fit Recruitment Model}

The traditional recruitment model Process is divided into three steps: First, determining the key requirements for a particular job through job analysis.Second, putting forward for the knowledge, skills and abilities each position should have. Third, designing the selection test to select the candidates whom KSAs are required by the position. Its main way is to interview.

However, in the person-organization fit recruitment, candidates are required no longer based on KSAs basic knowledge and skills.In addition, there are many other requirements,such as social skills, personal needs, values and personal interest requirements. Therefore, the process of this new pattern of recruitment should have many changes. The main steps summarized as follows:

\subsection{Job Analysis and Organizational Analysis for Vacancies}

Job analysis is an important foundation for the recruitment process. Not only provide the basis for recruitment, but also to reduce the recruitment of blindness, improve the relevance.The main content of the job analysis is shown in Figure 3:

\begin{tabular}{ll}
\hline Name & \multicolumn{1}{c}{ content } \\
\hline Job nature & $\begin{array}{l}\text { The general duties and obligations of the position. (e.g., management } \\
\text { positions, technical positions) }\end{array}$ \\
\hline Job functions & Specific tasks and functions \\
\hline Job time & How to arrange work time, and overtime profiles etc \\
\hline Job sites & work environment and working conditions \\
\hline Position reason & The significance and role in the enterprise \\
\hline Job conditions & $\begin{array}{l}\text { The position requirement for employees' ability and quality conditions. } \\
\text { Including culture, professional level, work experience, professional ethics, } \\
\text { etc }\end{array}$ \\
\hline Position compensation & Salary, welfare and promotion opportunity. \\
\hline
\end{tabular}

Figure 3. The main content of the job analysis

However, the new recruitment model also have organizational analysis. The purpose of the organizational analysis is to define and evaluate the work environment which based on the Job characteristics and organizational characteristics in itself. And clearing the key characteristics of the organization.Such as organizational culture, values, goals specification. Organizational analysis mainly includes four aspects:

\subsubsection{Organization Strategy Analysis}

Strategic analysis including tissue diagnosis and environmental analysis two parts. The main content is to analyze the organization's internal and external environment, industry structure, competitive advantage and disadvantage. It is mainly revealed in the organization's cost leadership strategy, focused strategy, differentiation strategy. 


\subsubsection{Organizational Culture Analysis}

Organizational culture analysis is based on the analysis of organizational culture survey. Using the basic method of dialectical thinking and modern scientific thinking to find out the advantages and disadvantages of organizational culture and the inherent law of organizational culture in the generation and development. The main contents includes the value of organized, institutional norms, environmental and behavioral culture.

\subsubsection{Interpersonal and Job-Related Environmental Analysis}

Interpersonal and job-related environmental analysis is divided into two aspects, one is the analysis of leadership or managerial behavior and leadership style; The other is the character analysis of the team members.

\subsubsection{Job Analysis}

The purpose of job analysis is to identify and determine the required knowledge, technology, ability and character who competent for this position. As long as a complete and comprehensive analysis of the required job responsibilities and qualifications fulfilled, person-organization fit recruitment can take the next step work.

\subsection{According to the Job Analysis to Infer the Type of Personnel Quality}

The evaluation of person-organization fit recruitment is divided into two aspects: on the one hand, according to the job analysis to infer the required KSAs staff needed, in order to achieve competency skills of individual employees.on the other hand, according to organizational analysis to conclude that the values, interests and personality employees should have. Therefore, the iceberg quality model appeared, as shown in Figure 4:

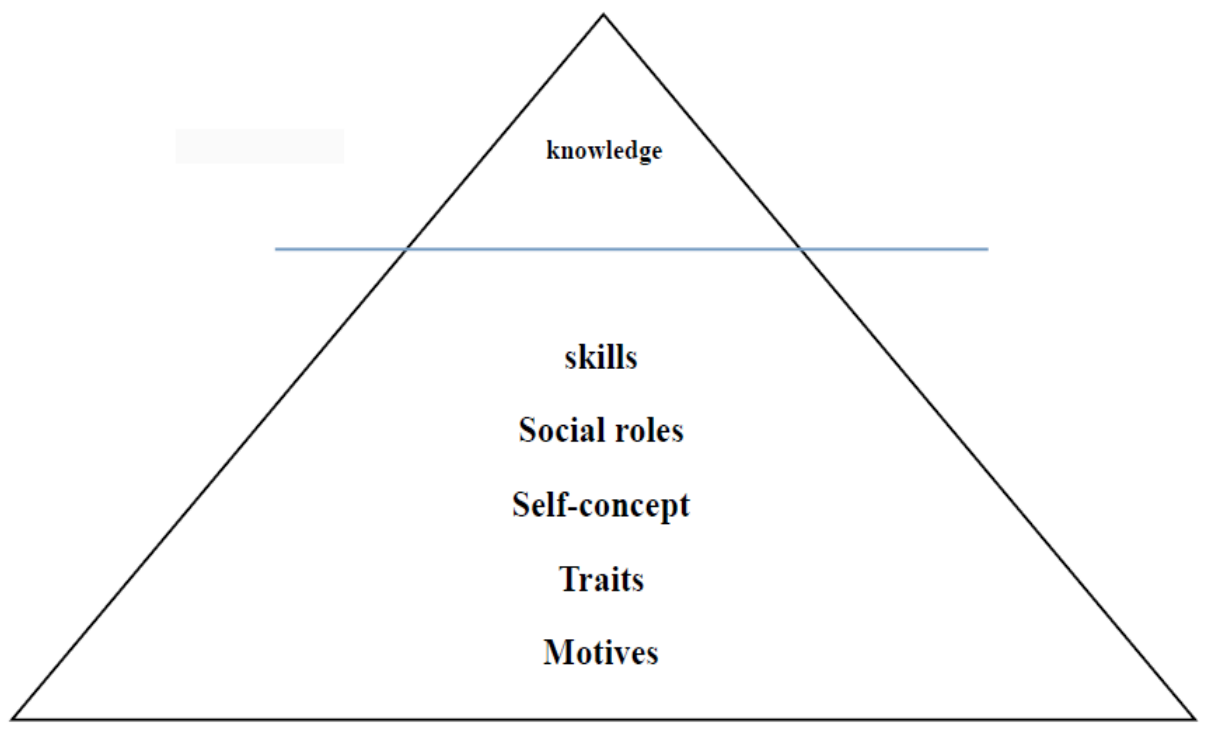

Figure 4. Iceberg quality model

In Figure 4, the tip of the upper "representation" requirements can be acquired through individual learning or upbringing. The general test and the interview often used these skills as an indicator of the evaluation. However, the "potential" requirements shown in the Iceberg below. including personality, self-image. It is difficult to be acquired through training and personal acquisition.Because it is the result of socialization. Thus, it play an important role in the evaluation and prediction of individual job performance.

\subsection{Designing Selection Technology and Matching Degree of the Organization}

The traditional recruitment model selection techniques based mainly on interviews. But person-organization fit recruitment model not only need to select a candidate's technical skills, but also need to select the interpersonal and social skills. The selection techniques mainly includes the following:

\subsubsection{Analysis}

This is a judgment method whether employees methods appropriate to the job by means of Analysis of individual background, work and life experiences.

\subsubsection{Cognition, Motivation, and Interpersonal Skills Test}

Evaluation of individual employees and the description of organizational culture. 


\subsubsection{Interview by Potential Colleagues or Others}

\subsubsection{Personality Test}

A text of the degree of matching job by use the personality measure.

\subsubsection{Real Work Preview}

This method is mainly to test a candidate's technical skills and interpersonal skills. At the same time, it can provide Organization's information for job seekers to facilitate organizations to make the selection.

Compared to person-organization fit recruitment model processes and traditional recruitment model, we can get Figure 5.

\begin{tabular}{lll}
\hline Process & Person-position fit & Person-organization fit \\
\hline $\begin{array}{l}\text { Work } \\
\text { environment } \\
\text { evaluation }\end{array}$ & Job analysis & Job analysis \\
Personnel & & Organizational analysis \\
inference & Knowledge & Social skills \\
& Skills & Personal interest demand values \\
& Ability & Personality traits \\
\hline $\begin{array}{l}\text { Screening } \\
\text { technology design }\end{array}$ & Interview & CV analysis \\
& & Cognition, motivation, and interpersonal skills test \\
& & Interviewing by potential colleagues \\
& & Personality test \\
& & Real work preview \\
\hline
\end{tabular}

Figure 5. Comparison of two modes of recruitment

\section{Limitations of Person-Organization Fit Recruitment Model}

Although the person-organization fit recruitment model have many advantages, but it also inevitably has some limitations in the implementation process.

\subsection{Higher Cost of Recruitment Process}

The person-organization fit recruitment model need to adopt a variety of screening technology, so the cost is indispensable in the process. With the development of organization, the organization's business, technology and culture has been changing, which requires the recruitment model will also change. It also caused higher costs. Meanwhile, under the new organization pattern of recruitment, the hiring process time is relatively long, and requirement of recruiters will become more and more.which requires managers must have sufficient professional staff and adequate training of personnel, it can also lead to increased costs.

\subsection{The Selection of Technology Is Immature}

The staff recruitment based on person-organization fit is the key to effectively measure the similarity between job characteristics and organizational characteristics. Compared with the traditional recruitment model, the traditional recruitment model evaluation and assessment techniques about KSAs are more mature than personality traits. At the same time, the evaluation of organization and work environment is not more extensive use than job analysis technology.

As shown in Figure 5, the person-organization fit Recruitment's content and depth has been extended. It caused Screening technology has not formed a complete system. The immature screening technology affects the new recruitment pattern practice.

\subsection{Organizations Lack of Innovation}

Person-organization fit is the dynamic matching. It requires each employee's personal values, interests, personality and so on all match to the organization. It'll be easier to cause each staff has the same values, strengths, weaknesses and blind spots, which result in make the organization become slow. We can find that some studies have confirmed this view: Dension is pointed out that the organization which have small differences in opinions between internal 
staff may run better in the short term, but the organizational business deteriorated because of poor adaptability after a long time. Corresponding, Schneider believes people matching organization with the high degree will make all staff more tend to be "homogeneous", which has the same character and personality traits. So it inhibits the innovation of the enterprise and reduces the innovation ability of organization, which led to a decline in organizational effectiveness. Especially the "homogeneous" of manager will appear more serious consequences.

\section{New Strategy of Person-Organization Fit}

The person-organization fit recruitment model considers that we should have the insight into the development of every problem. Researchers should be further strengthened to match individuals and organizations, and explore more use of Person-organization fit in human resource management.

\subsection{Control Recruitment Costs}

We should pay attention to how to effectively control costs. Firstly, we'd better organize own professional recruitment team or entrust other institutions. It can reduce the cost of hiring expert. Secondly, technology selection should grasp the key tests and ignore some unnecessary tests in order to reduce costs. Finally, after the recruitment activity, managers should be timely summarizes the harvest and the insufficiency of the recruitment. It can avoid repeating unnecessary costs in the process of new recruitment.

\subsection{Designing Screening Technology Combined with Practice}

Enterprises must be good at design selection techniques which suitable for themselves. First of all, organizations should effectively assess organizational characteristics, and select the effective measurement scale or related personnel evaluation method according to the importance of the employees. Secondly, we should timely innovate new testing technology and apply in each process. Finally, after the recruitment, managers should find out problems and improve screening technology.

\subsection{Cultivating Innovative Talents to Create Innovative Organization}

Organization should give full play to the role of complementary matching in the process of recruitment. Not only consider the age structure of the candidates of the organization, academic qualifications, work experience, personality characteristics and capabilities, but also to take into account the matching between its various qualities. Therefore, managers should establish company personnel archives so that can be read at any time. In addition, managers should adopt the individual socialization strategy to shape the creative character of new employees. Such as teacher and pupil learning, random training, encourage employees to develop a variety of roles adaptive mode.

\section{References}

A. L. Kristof. (1996). Person-organization fit: An integrative review of its conceptualizations, measurement, and Implications.

D. R. Dension. (1990). Corporate culture and organizational effectiveness.

$\mathrm{Hu}$, Yang, \& Liu, Guohua. (2007). Research on human and organizational human resource management strategy match. Financial Reform Forum, (6).

Liu, Xiaoyu, \& Wang, Duanxu. (2006). Person-organization fit research progress. Journal of technology economy and management research, (2).

Miao, Ziguang, \& Fu, Jijuan. (2005). Measuring method and the means of person-organization fit. Journal of economics and management, (1).

Schneider B.H W. Goldstein. (1995). The ASA framework: An update.

Wang, Ping, \& Zhang, Kuanyu. (2008). Impact on the effectiveness of the Person-organization fit. East China Economic Management.

Ye, Zechuan. (1999). Person-organization fit research review. 